\title{
Adrenergic Modulation of Pancreatic Hormone Secretion in Utero: Studies in Fetal Sheep
}

\author{
MARK A. SPERLING, ${ }^{(40)}$ RONALD A. CHRISTENSEN SUPRIYA GANGULI, AND RAJEN ANAND \\ Department of Pediatrics, Division of Endocrinology and Metabolism, University of California, Los Angeles, School of \\ Medicine, Harbor General Hospital Campus, Torrance, California USA
}

\section{Summary}

To assess the functional maturity of adrenergic modulation of plasma concentration of glucose, as well as immunoreactive glucagon (IRG) and immunoreactive insulin (IRI) secretion in utero, adrenergic agonists with or without $\beta$ (propranolol) or $\alpha$ (phentolamine) antagonists were infused to the chronically catheterized sheep fetus $(n=35)$ late in the third trimester. Mean \pm S.E. days at study was $129.5 \pm 1.5$; term is 150 days. In 9 separate studies at gestational age $129 \pm 1$ days, the infusion of saline for $3 \mathrm{hr}$ was not associated with significant changes in the basal levels of glucose, IRG, or IRI.

With epinephrine, $6 \mu \mathrm{g} / \mathrm{min}(n=6)$ glucose rose from $16.7 \pm$ 3.6 to $41.9 \pm 9.7 \mathrm{mg} / \mathrm{dl}$, IRG rose from $75 \pm 8$ to $219 \pm 45 \mathrm{pg} / \mathrm{ml}$, and IRI fell from $22.6 \pm 1.7$ to $12.7 \pm 3.5$ microunits $/ \mathrm{ml}(P<0.05$ for each). Propranolol alone $(n=4)$ did not alter basal glucose or IRG but significantly suppressed IRI. Propranolol did, however, markedly attentuate the rise in glucose and IRG while exaggerating the fall in IRI during epinephrine infusion. Qualitatively similar but smaller responses were obtained with epinephrine, 0.4 $\mu \mathrm{g} / \mathrm{min}(n=10)$. Similarly, elevation of glucose and suppression of IRI was obtained with norepinephrine, $2 \mu \mathrm{g} / \mathrm{min}(n=5)$, but IRG levels did not rise significantly. $\alpha$-Adrenergic blockade alone augmented IRI from $18 \pm 3$ to $38 \pm 5$ microunits/ml without affecting glucose or IRG concentrations; during $\alpha$ blockade, norepinephrine infusion failed to induce the rise in glucose, IRG remained unchanged, and IRI remained elevated $(n=5)$. 2-DeoxyD-glucose, $200 \mathrm{mg}$ IV over $30 \mathrm{~min}$, did not affect glucose, IRG, or IRI $(n=5)$. Thus, appropriate adrenergic modulation of plasma concentrations of glucose, and of IRG and IRI secretion is established in the third trimester.

\section{Speculation}

Many of the metabolic adaptations that characterize the transition from intrauterine to extrauterine energy homeostasis are suggestive of a catecholamine effect. These changes include a surge in plasma immunoreactive glucagon concentrations, low immunoreactive insulin levels, an initial fall followed by stabilization of blood glucose, and a rapid rise in free fatty acid levels. An abrupt but brief increase in arterial plasma concentrations of epinephrine and norepinephrine also occurs at birth. In the present studies, infusion of epinephrine in utero simulated those changes that usually occur after birth, thereby suggesting that catecholamines are a major trigger for neonatal energy adaptations that involve insulin and glucagon secretion.

The orderly transition of energy homeostasis from intrauterine to extrauterine life requires several important adaptations that involve hormones, substrates, and enzymes $(15,18,37)$. Of the pancreatic hormones, plasma immunoreactive insulin concentrations (IRI) remain low, whereas immunoreactive glucagon (IRG) concentrations in plasma increase 3- to 5-fold shortly after delivery in both humans and rats $(15,17)$. The rise in IRG correlates inversely to the transient fall in glucose during the initial hours following placental separation and abrupt cessation of the transfer of nutrients from mother to fetus, thereby suggesting that hypoglycemia acts as the stimulus for the observed changes $(15,17)$. We have recently reported that in newborn lambs there is a similar 5 -fold surge of IRG within minutes of delivery, whereas plasma IRI remains low and unchanged (17). In newborn lambs, however, there was no fall in plasma glucose concentration following delivery, so that unless curtailment of a different major nutrient for the lamb acts as the trigger for IRG secretion, hypoglycemia is not the stimulus for the observed surge in IRG. An abrupt increase in catecholamine secretion at birth could adequately explain the observed changes because catecholamines are known to stimulate glucagon secretion, inhibit insulin secretion, and mobilize free fatty acids $(9,12,19,23,26,29,32,38)$. A rise in circulating free fatty acid levels does occur shortly after delivery $(1,17)$. Moreover, catecholamines increase markedly and abruptly in the arterial plasma of newborns at delivery $(10,24)$, and urinary excretion of epinephrine increases in the initial hours of life (27). If this hypothesis regarding the role of catecholamines as the trigger for the observed neonatal changes were correct, then the appropriate metabolic response to catecholamines should be established in utero, and infusion of catecholamines directly to the fetus in utero may simulate those metabolic events which normally take place after birth, although in the case of the neurotransmitter, norepinephrine, plasma concentrations will underestimate local tissue concentrations because of local axonal reuptake and hence conservation of tissue concentrations (25). The present studies were undertaken to test the hypothesis that certain metabolic adaptations at birth may be due to catecholamines through infusion of various adrenergic agonists with and without adrenergic blocking drugs to the sheep fetus during the third trimester.

\section{MATERIALS AND METHODS}

Healthy date-bred ewes of Columbia-Suffolk strain with gestational ages greater than 110 days were studied. The chronic indwelling catheter preparation which has been previously described was utilized $(17,35)$. After an overnight fast, a laparotomy was performed through a flank incision using intramuscular ketamine, local anesthesia, and aseptic technique. Following uterotomy, the fetal head was delivered taking appropriate caution to prevent disruption of the fetal membranes. Through a small incision in the membranes, a fetal jugular vein and carotid artery were exposed and catheterized. Following catheter placement, the fetus was returned to the uterine cavity, and all incisions were closed. The catheters were exteriorized, marked, and secured in a pouch fixed to the mother's back. The ewes began ambulation immediately following the procedure. Ampicillin, $500 \mathrm{mg}$ IM to the mother and $250 \mathrm{mg}$ via the venous catheter to the fetus, was administered daily for 4 days. Except on the day of study, catheters were irrigated daily with $4 \mathrm{ml}$ of heparinized saline solution containing 100 units/ml. Studies were performed 48 to $72 \mathrm{hr}$ postsurgery, at which time maternal dietary intake had fully resumed, and arterial gasses and $\mathrm{pH}$ of fetal blood were normal $\left(\mathrm{pH}=7.35 \pm 0.1 ; \mathrm{pO}_{2}=24 \pm 1.0 ; \mathrm{pCO}_{2}=41 \pm 1.1\right)$.

The mean gestational age of the fetuses in the study group ( $n$ 
$=35$ ) was $129.5 \pm 1.5$ days (mean \pm S.E.); the normal gestational period is approximately 150 days. There was no significant difference in the mean fetal gestational age among the various study groups. To prevent agitation, studies were undertaken with the maternal sheep in a stall without restraint. To control for the effects of infusion alone, 9 separate studies were performed in which saline was infused over $3 \mathrm{hr}$ at rates calculated to provide total volume similar to that of the study group. The mean gestational age of this control group was $128 \pm 1$ days.

All adrenergic agents were diluted in 0.85 sodium chloride immediately prior to use and administered by controlled infusion via the fetal venous catheter using a Harvard pump (Harvard Apparatus Co., Inc., Millis, MA). Epinephrine (Parke, Davis and Co., Detroit, MI) was infused for $60 \mathrm{~min}$ in two separate series of studies to determine if a dose response relationship existed. In one series, epinephrine was infused constantly at $6 \mu \mathrm{g} / \mathrm{min}$, and in the second, it was infused at $0.4 \mu \mathrm{g} / \mathrm{min}$ (approximately $0.1 \mu \mathrm{g} / \mathrm{kg}$ ) min).

To examine the effect of $\beta$-adrenergic receptor blockade, propranolol (Inderal; Ayerst Labs., Inc., New York, N. Y.) was administered as a priming bolus of $100 \mu \mathrm{g}$ followed by an infusion of $8 \mu \mathrm{g} / \mathrm{min}$ for $105 \mathrm{~min}$. Propranolol alone was given for $45 \mathrm{~min}$, at which time epinephrine was added to the infusate for a further $60 \mathrm{~min}$. Thus, the effects of the adrenergic blockade alone for $\mathbf{4 5}$ min and its influence on the subsequent response to epinephrine for a further hour were examined. In separate experiments, norepinephrine bitartrate (levophed; Winthrop Labs, New York, N. Y.) was infused at a rate of $2 \mu \mathrm{g} / \mathrm{min}$ for $60 \mathrm{~min}$, either alone or in the presence of $\alpha$-adrenergic blockade. The influence of $\alpha$ adrenergic blockade was investigated via phentolamine (Regitine, Mesylate; Ciba-Geigy Corp., Nutley, N. J.). Phentolamine, 200 $\mu \mathrm{g}$ as a priming dose was followed immediately by an infusion of $40 \mu \mathrm{g} / \mathrm{min}$ for $105 \mathrm{~min}$. Phentolamine alone was infused for 45 min, at which time norepinephrine was added to the infusate for a further $60 \mathrm{~min}$.

In an attempt to provoke a spontaneous surge in catecholamines, 2-deoxy-D-glucose (Sigma Chemicals Co., St. Louis, MO) was infused as $200 \mathrm{mg}$ over $30 \mathrm{~min}$, i.e., approximately $50 \mathrm{mg} / \mathrm{kg}$. 2-Deoxyglucose induces intracellular glucopenia, the counter regulation of which is accomplished by a series of hormonal events including catecholamine secretion $(4,5,11,34)$.

In each experiment, after a period of $\mathrm{I} \mathrm{hr}$ to allow the ewe to become adjusted to her surroundings, sequential blood samples were withdrawn through the fetal carotid artery catheter before and again during the infusion of the saline or test substance(s) at the times indicated in Table 1 and Figures 1 to 4 . The initial value represents the mean of 2 samples drawn $30 \mathrm{~min}$ apart prior to commencing experiments.

Each blood sample of $3 \mathrm{ml}$ was placed into chilled tubes containing EDTA and 1500 kallikrein inhibitory units of aprotinin (Trasylol), an inhibitor of glucagon degradation. The plasma was separated promptly in a refrigerated centrifuge and stored frozen at $-20^{\circ} \mathrm{C}$ until assayed.

\section{ANALYTIC TECHNIQUE}

Glucose was measured by a glucose oxidase method calibrated to provide accurate measurements of values 5 to $100 \mathrm{mg} / \mathrm{dl}(28)$.
Insulin and glucagon were measured by radioimmunoassay using methods previously described $(36,37)$. The glucagon antibody used, Gl-5, is highly discriminating for pancreatic glucagon and cross-reacts minimally with gut extracts $(36,37)$. Rabbit antiporcine antibody was used, and porcine insulin was used for labeling and standards. Ovine insulin and ovine serum provides parallel dose-response curves in the assay (17). For each hormone, all samples in the study groups were measured in a single assay run to avoid interassay variation. Similarly, for each hormone in the saline-infused group, all samples were measured in a single assay run. The intra-assay coefficient of variation was less than $10 \%$ for

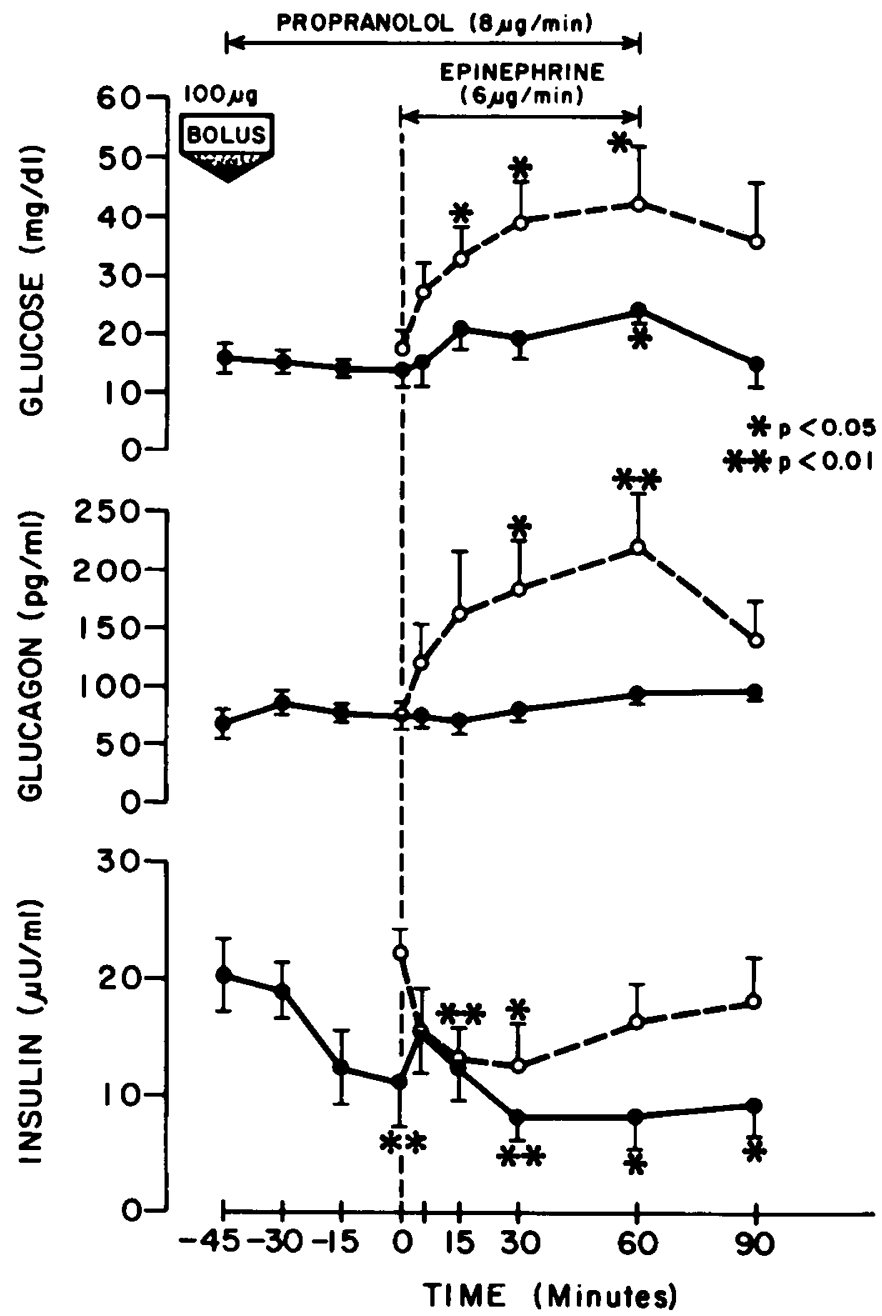

Fig. 1. Effects if epinephrine, $6 \mu \mathrm{g} / \mathrm{min}$, alone $(\mathrm{O} n=7)$ or during $\beta$ adrenergic blockade with propranolol $(\theta, n=4)$ on plasma glucose, glucagon (IRG), and insulin (IRI) in fetal sheep. Bars, S.E. Asterisks, significant difference from starting value at 0 time or $-45 \mathrm{~min}$, respectively. In addition, there are significant differences between the two treatment schedules at 30 and $60 \mathrm{~min}$ for glucose and IRG and at $60 \mathrm{~min}$ for IRI.

Table 1. Plasma glucose, and insulin during saline infusion in fetal sheep

\begin{tabular}{lccccc}
\hline & \multicolumn{4}{c}{ Time after starting saline (min) } \\
\cline { 2 - 6 } & 0 & 30 & 60 & 120 & 180 \\
\hline $\begin{array}{c}\text { Glucose } \\
(\mathrm{mg} / \mathrm{d} ; n=9)\end{array}$ & $17.4 \pm 2.0$ & $21.1 \pm 2.6$ & $19.0 \pm 2.1$ & $21.1 \pm 2.3$ & $20.2 \pm 1.7$ \\
$\begin{array}{c}\text { Glucagon } \\
\quad(\mathrm{pg} / \mathrm{ml} n=4)\end{array}$ & $70.0 \pm 9.8$ & $62.0 \pm 4.8$ & $67.0 \pm 7.1$ & $80.0 \pm 11.0$ & $83.0 \pm 15.0$ \\
$\begin{array}{c}\text { Insulin } \\
\text { micro units/ml, } n=9)\end{array}$ & $16.7 \pm 1.9$ & $17.6 \pm 1.4$ & $17.1 \pm 2.7$ & $20.1 \pm 2.4$ & $19.0 \pm 2.5$ \\
\hline
\end{tabular}

\footnotetext{
'The gestational age of all the fetuses was $128 \pm 1$ days; that of the 4 fetuses in whom glucagon was measured was $130 \pm 1.4$.
} 


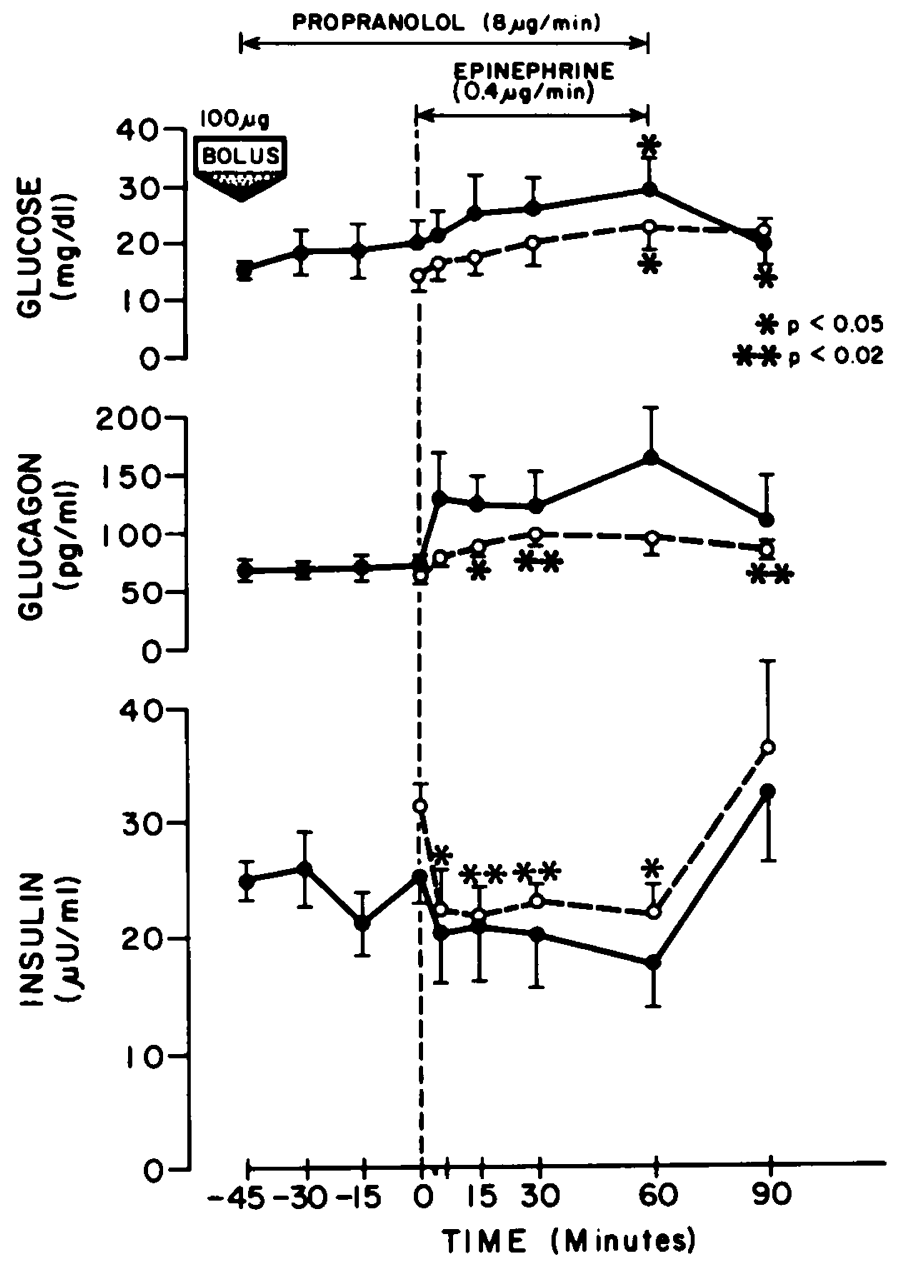

Fig. 2. Effects of epinephrine, $0.4 \mu \mathrm{g} / \mathrm{min}$, alone $(\mathrm{O}, n=5)$ or during $\beta$-adrenergic blockade with propranolol $(\Theta, n=5)$ on plasma glucose, IRG, and IRI in fetal sheep. Bars, S.E. Asterisks, significant difference from starting value respectively at 0 time or $-45 \mathrm{~min}$.

each hormone. Statistical analysis within and between groups used Student's test, paired or unpaired, and analysis of variance.

RESULTS

CONTROL. STUDIES

The effects of saline infusion for $3 \mathrm{hr}$ on plasma glucose, IRG, and IRI are shown in Table 1 . There were no significant changes in any of the measured variables throughout the period of saline infusion. Moreover, the concentrations of each variable were similar to the basal values in each of the study groups. Although glucagon was measured in only 4 of 9 studies, the mean \pm S.E. of the plasma levels did not vary significantly from the basal values in the study groups. Thus, the changes observed during infusion of the adrenergic agents with or without the respective blocking agents and the changes observed during infusion of the blocking agent alone cannot be ascribed to the nonspecific stress of the infusion procedure.

\section{EFFECTS OF EPINEPHRINE. $6 \mu \mathrm{g} / \mathrm{min}$ (FIG. 1 )}

Six studies were performed in lamb fetuses of gestational age 121 to 145 days, mean, $133 \pm 4$ days. Glucose rose from $16.7 \pm$ $3.6 \mathrm{mg} / \mathrm{dl}$ at 0 time to a peak value of $41.9 \pm 9.7 \mathrm{mg} / \mathrm{dl}$ at $60 \mathrm{~min}$. Values from 15 through $60 \mathrm{~min}$ were significantly higher than basal $(P<0.05)$. Glucagon rose from $75 \pm 8 \mathrm{pg} / \mathrm{ml}$ at 0 time to a peak of $219 \pm 45 \mathrm{pg} / \mathrm{ml}$ at $60 \mathrm{~min}(P<0.01)$. Insulin fell from $22.6 \pm 1.7$ microunits $/ \mathrm{ml}$ at 0 time to a nadir of $12.7 \pm 3.5$ microunits $/ \mathrm{ml}$ at $30 \mathrm{~min}$. The insulin values at 15 and $30 \mathrm{~min}$ were significantly below basal $(P<0.01$ and $P<0.05$, respectively). Upon cessation of infusion at $60 \mathrm{~min}$, all variables returned towards basal, and by $90 \mathrm{~min}$, none were significantly different from basal values.

\section{INFLUENCE OF $\beta$-ADRENERGIC BLOCKADE (FIG. 1)}

Four studies were performed at gestational age 112-131 days (mean, $121 \pm 4$ days). Propranolol alone for $\mathbf{4 5} \mathrm{min}$ had no effect on basal glucose values of $15.5 \pm 1.5 \mathrm{mg} / \mathrm{dl}$. However, the response to epinephrine was markedly attenuated so that the peak value at $60 \mathrm{~min}$ was $24.1 \pm 2.1 \mathrm{mg} / \mathrm{dl}$. Although higher than basal $(P<$ 0.05 , cf. 0 time), the glucose rise during epinephrine with propranolol was significantly less than without propranolol $(P<0.05)$. Similarly, propranolol alone did not affect basal glucagon, but markedly attenuated the response to epinephrine $(P<0.01)$. The peak value of $96 \pm 8 \mathrm{pg} / \mathrm{ml}$ was not signficantly increased above the basal value of $68 \pm 12 \mathrm{pg} / \mathrm{ml}$. In contrast, in response to propranolol alone, basal insulin values of $20.3 \pm 2.8$ microunits/ $\mathrm{ml}$ fell to $11.3 \pm 3.8 \mathrm{microunits} / \mathrm{ml}$ at 0 time $(P<0.01$ by paired $t$ analysis). With addition of epinephrine, there was a further fall to a nadir of $8.3 \pm 2.6 \mathrm{microunits} / \mathrm{ml}$ at $60 \mathrm{~min}$. Values at 30 and 60 min were significantly less $(P<0.01$ and $P<0.05$, respectively) than the starting value and remained significantly depressed 30 min following cessation of infusion.

EFFECTS OF EPINEPHRINE $0.4 \mu \mathrm{g} / \mathrm{min}$ (FIG. 2)

Five animals were studied at gestational age 124 to 141 days (mean $132 \pm 3$ days). The higher dose of epinephrine had been used in anticipation of placental transfer of this hormone $(10,24)$

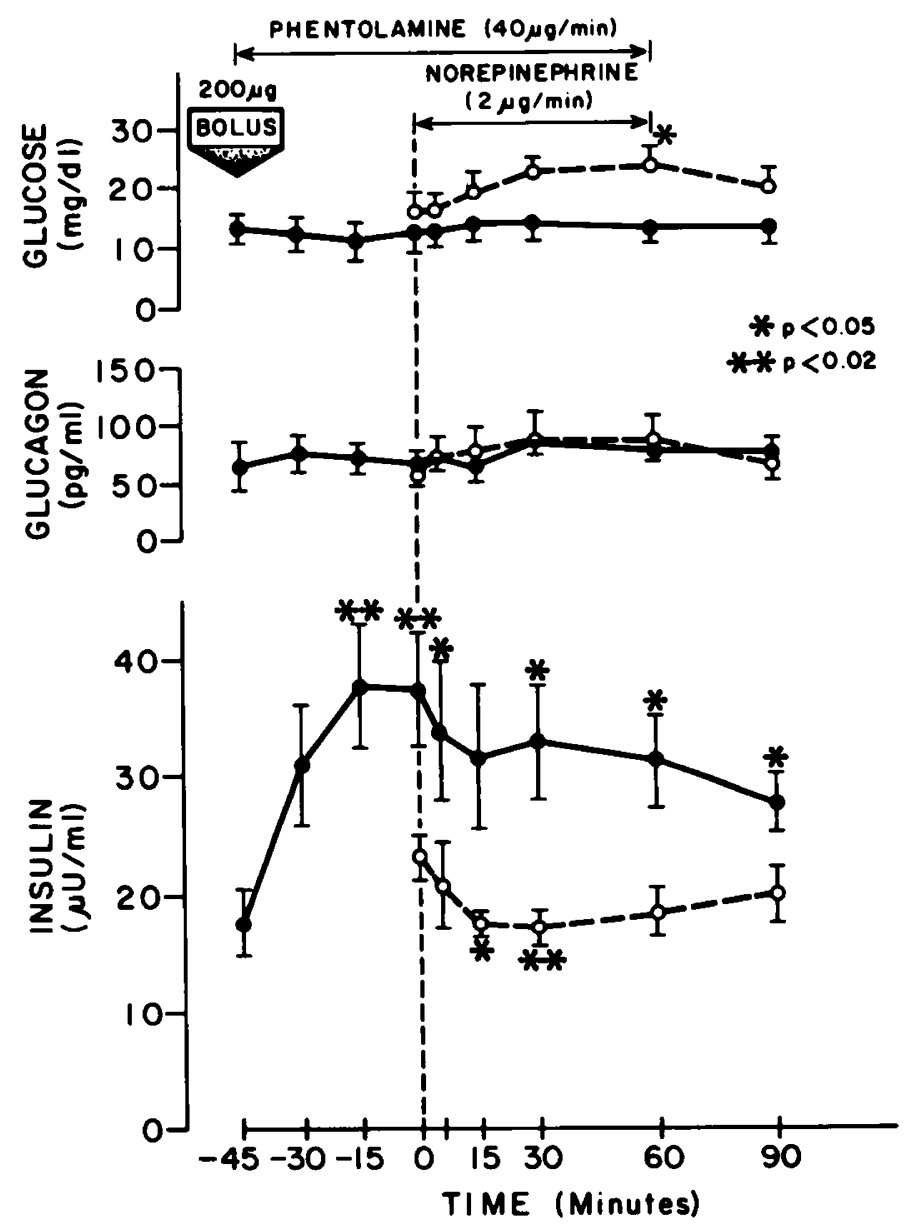

Fig. 3. Effects of norepinephrine, $2 \mu \mathrm{g} / \mathrm{min}$, alone $(O, n=5)$ or during $\alpha$-adrenergic blockade with phentolamine $(Q, n=5)$ on plasma glucose, IRG, and IRI in fetal sheep. Bars, S.E. Asterisks, significant difference from starting value respectively at 0 time for $-45 \mathrm{~min}$. In addition, there are significant differences between the two treatment schedules for glucose at $60 \mathrm{~min}$ and for IRI at 30 and $60 \mathrm{~min}$. 


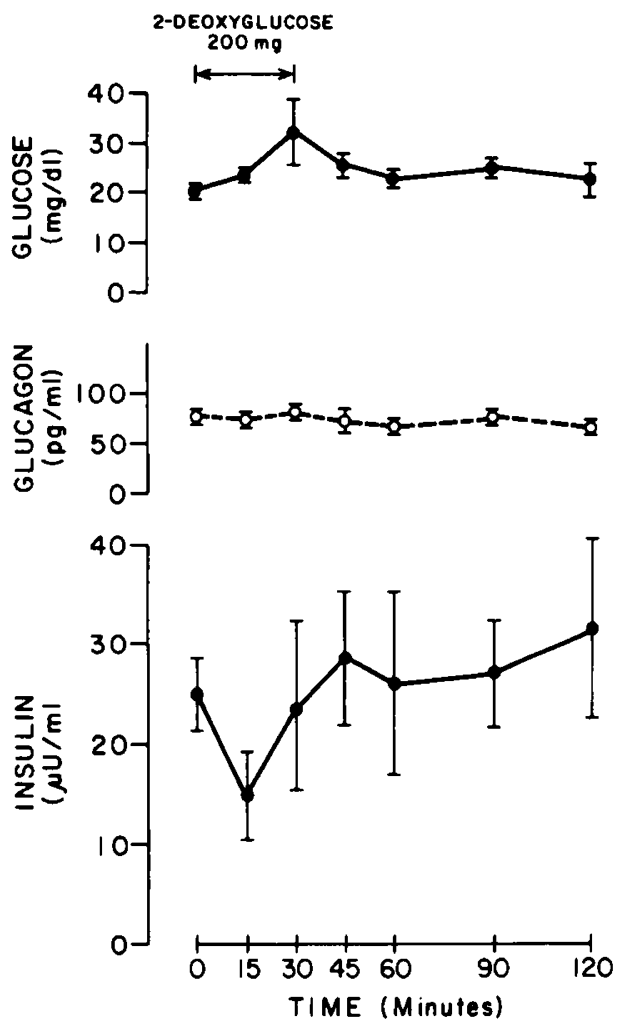

Fig. 4. Effect of 2-deoxy-D-glucose $200 \mathrm{mg}$ over $30 \mathrm{~min}$ on plasma glucose, IRG, and IRI in fetal sheep $(n=5)$. Bars, S.E. There are no significant changes in any of the variables.

and thus dilution of effect through mixing in both fetal and maternal compartments. The standard dose of epinephrine used in studies in adults is $6 \mu \mathrm{g} / \mathrm{min}(13,33)$, representing approximately $0.1 \mu \mathrm{g} / \mathrm{kg} / \mathrm{min}$. Therefore, to examine the effect of this dose infused directly to the fetus, a fetal weight of $4 \mathrm{~kg}$ was assumed for all fetuses, and $0.4 \mu \mathrm{g} / \mathrm{min}$ was given.

Glucose rose from $14.3 \pm 2.4 \mathrm{mg} / \mathrm{dl}$ at 0 time to a peak value of $22.6 \pm 3.6 \mathrm{mg} / \mathrm{dl}$ at $60 \mathrm{~min}$. Although significantly above basal $(P<0.05)$, this value is less than peak response obtained with the higher dose of epinephrine. Glucagon rose from $65 \pm 6 \mathrm{pg} / \mathrm{ml}$ at 0 time peak value of $98 \pm 9 \mathrm{pg} / \mathrm{ml}$ at $30 \mathrm{~min}$. Again, this value is significantly above basal $(P<0.02)$ but less than the peak observed with the higher dose of epinephrine $(P<0.05)$. Insulin fell from $31.6 \pm 1.8$ microunits $/ \mathrm{ml}$ at 0 time to a nadir of $22.0 \pm 2.6$ at 60 $\min (P<0.02)$. All values from 5 through $60 \mathrm{~min}$ were significantly lower than were basal values. Thus, for all 3 variables, the responses to $0.4 \mu \mathrm{g} / \mathrm{min}$ were qualitatively similar, although for glucose and IRG, they were quantitatively less than the responses to $6 \mu \mathrm{g} / \mathrm{min}$. Propranolol modified the response to epinephrine, $0.4 \mu \mathrm{g} / \mathrm{min}$, in a manner similar to that described above for the higher dose of epinephrine. Thus, the rise in glucose was modest, and the glucagon response was attenuated; although glucagon values rose above basal, none were statistically significant. However, in this study propranolol failed to suppress basal IRI or to amplify the effects of low dose epinephrine on suppressing insulin secretion. No clear explanation can be given for these results. However, cessation of all infusion resulted in a rebound rise in insulin.

\section{EFFECTS OF NOREPINEPHRINE. $2 \mu \mathrm{g} / \mathrm{min}$ (FIG. 3)}

Five animals of gestational age 120 to 138 days $(131 \pm 2)$ were studied. At this dose of norepinephrine, glucose rose from $15.6 \pm$ $4 \mathrm{mg} / \mathrm{dl}$ to a peak of $23.4 \pm 2.9 \mathrm{mg} / \mathrm{dl}$ at $60 \mathrm{~min}(P<0.05)$, and IRG rose from $59 \pm 11 \mathrm{pg} / \mathrm{ml}$ to a peak of $87 \pm 23 \mathrm{pg} / \mathrm{ml}$; this change was not statistically significant. In contrast, IRI fell from the basal value of $23.3 \pm 1.8$ microunits $/ \mathrm{ml}$ to $17.6 \pm 1.2$ microun- its $/ \mathrm{ml}$ and $17.1 \pm 1.4$ microunits $/ \mathrm{ml}$ at 15 and $30 \mathrm{~min}(P<0.05$ and $P<0.02$ ), respectively.

\section{INFLUENCE OF $\alpha$-ADRENERGIC BLOCKADE (FIG. 3)}

Five studies were performed at gestational age 113 to 136 days (mean, $123 \pm 4$ days). Phentolamine alone failed to modify basal glucose or IRG. However, IRI rose markedly from $17.8 \pm 2.7$ microunits $/ \mathrm{ml}$ to levels of $37.6 \pm 5.3$ and $37.2 \pm 4.7$ microunits/ $\mathrm{ml} 30$ and $45 \mathrm{~min}$ after phentolamine infusion $(P<0.02$ for each). Addition of norepinephrine did not change glucose concentrations; at $60 \mathrm{~min}$, the glucose concentration of $12.9 \pm 2.6 \mathrm{mg} / \mathrm{dl}$ was less than the value of $23.4 \pm 2.9 \mathrm{mg} / \mathrm{dl}$ with norepinephrine alone $(P<0.05)$. Similarly, addition of norepinephrine during ongoing phentolamine did not result in changes of plasma IRG. However, in the presence of $\alpha$-blockade, norepinephrine did not suppress IRI, and all values remained significantly elevated above preinfusion levels, even after all infusion ceased. The difference in IRI response to norepinephrine with and without $\alpha$-adrenergic blockade was striking $(P<0.05$ at 0 time; $P<0.02$ at 30 and 60 $\min$ ).

\section{EFFECTS OF 2-DEOXYGLUCOSE $2 \mu \mathrm{g} / \mathrm{min}$ (FIG. 3)}

Five animals were studied at gestational age 118 to 139 days (mean, $131 \pm 4$ days). Infusion of $200 \mathrm{mg}$ of 2-deoxyglucose over $30 \mathrm{~min}$ did not elicit significant responses in glucose, IRG, or IRI. There appeared to be a rise in glucose from $19.7 \pm 1.7$ to $32 \pm 6.4$ $\mathrm{mg} / \mathrm{dl}$, but this change was not significant by paired or unpaired $t$ test. Similarly, the apparent fall in IRI from $25.1 \pm 3.4$ to 14.7 \pm 4.4 microunits $/ \mathrm{ml}$ was not significant.

\section{DISCUSSION}

The present studies were undertaken to assess whether adrenergic agonists and/or blocking agents can modulate fetal pancreatic hormone secretion in utero and to test the hypothesis that a surge of catecholamine secretion at birth may be responsible for several changes in substrates and pancreatic hormones that appear shortly after birth, changes that may represent key adaptations in neonatal energy homeostasis. For these changes to occur at birth, there must be progressive maturation in utero of the capacity to secrete catecholamines as well as the ability for appropriate hormone and substrate response to catecholamine secretion and the modulation of these responses by $\alpha$ and $\beta$ adrenergic receptors. In response to hypoxia, the fetal lamb in the third trimester increases secretion of epineprine and norepinephrine $(7,8)$ such that plasma concentrations (22) approximate those found in the umbilical artery plasma of normal human newborns $(10,24)$; even higher plasma concentrations are found in the cord blood of asphyxiated newborn humans (24). Plasma concentrations of epinephrine that approximate those found with modest hypoxia can be achieved in fetal sheep through constant infusion at doses that exceed $0.4 \mu \mathrm{g} /$ $\mathrm{kg} / \mathrm{min}(7)$. In view of the rapid metabolic clearance of catecholamines (half life $<1 \mathrm{~min}$ ) (22) and the possibility of transplacental transfer of catecholamines (24), our initial experiments with epinephrine infusion used $6 \mu \mathrm{g} / \mathrm{min}$, a dose commonly used in adult organisms $(13,33)$. Subsequent experiments with epinephrine used a dose of $0.1 \mu \mathrm{g} / \mathrm{kg} / \mathrm{min}$ based on an estimated fetal weight of 4 $\mathrm{kg}$. This dose is clearly less than that required to simulate concentrations achieved during experimentally induced fetal hypoxia (22). The dose of norepinephrine used, $2 \mu \mathrm{g} / \mathrm{min}$, is, however, in the range required to simulate fetal plasma concentrations during hypoxia, although they may not reflect tissue concentrations that may be higher (25). Doses of the blocking agents propranolol and phentolamine were adjusted for estimated body weight and reduced to approximately one-tenth of those used in adults $(9,12$, 32,33 ). Doses of 2-deoxyglucose (4) were estimated on the basis of body size as used in other investigations. Thus, experimental manipulations were designed to approximate endogenous concentrations of catecholamines that may be present in utero during stress or that are present in umbilical artery plasma at delivery 
and in particular to simulate perturbations that are known to affect pancreatic hormone secretion in the adult organism.

Hemodynamic responses to adrenergic agonists and blocking agents have been extensively investigated in the fetus (2, 31). There are, however, no reported studies in the fetus that assess the sequential pancreatic endocrine and metabolic response to infusion of adrenergic agents with and without $\alpha$ and $\beta$ adrenergic blockade. Girard et al., (16) reported a marked increase in plasma IRG and fall in plasma IRI $30 \mathrm{~min}$ after a single large dose of norepinephrine given to the fetal rat pup. In vitro, epinephrine increases IRG release from monolayer cultures of newborn rat pancreas (30).

Epinephrine, $6 \mu \mathrm{g} / \mathrm{min}$, induced a prompt rise in plasma glucose and IRG and a fall in IRI. The magnitude in the rise of glucose is similar to that previously reported in the fetal lamb during hypoxia or epinephrine infusion (21). The rise in IRG of approximately 3-fold approximates closely the spontaneous surge observed in the newborn of several species including lamb and human neonates $(15,17,35)$. Suppression of IRI by epineprine is consistent with the known effects of this adrenergic agonist on insulin secretion $(9,31,33,38)$. $\beta$-Adrenergic blockade via propranolol markedly attentuated but did not totally prevent the glycemic response, in keeping with other reports (9) and with the dual activation of hepatic glycogenolysis by both $\alpha$ - and $\beta$-adrenergic activation (6). The complete prevention of the rise in IRG by propranolol is consistent with the concept that $\beta$-adrenergic receptor activation is predominately responsible for adrenergically induced IRG secretion $(12,13,19)$, although some investigations dispute this conclusion (38). Finally, the demonstration of the fall in IRI by propranolol is in keeping with the predominant role of $\beta$-adrenergic activation in insulin secretion $(9,19,32,33,38)$. Thus, with respect to glucose, IRG, and IRI at these doses of epinephrine and propranolol, the lamb fetus in the third trimester manifests responses that are typical of the adult organism, suggesting that appropriate adrenergic modulation is established at this stage of gestation. Furthermore, there were qualitatively similar responses during the smaller dose of epinephrine. Inasmuch as this lower dose of epinephrine was submaximal and not likely to achieve plasma concentrations observed with anoxia (22) or at birth $(10,24)$, there appears to be a dose-dependent response that is operational in utero. Nevertheless, in the absence of measurements of plasma epinephrine levels, it cannot be claimed that the plasma levels achieved with exogenous infusion reflected physiological events.

The response to norepinephrine further substantiates the functional maturity of the autonomic modulation of glucose, IRG, and IRI in utero. Thus, the rise in glucose induced by norepinephrine was prevented by $\alpha$-adrenergic blockade (6), whereas the fall in IRI was prevented by phentolamine $(9,13,32,38)$. Indeed, $\alpha$ adrenergic blockade alone resulted in a significant rise in IRI which was sustained during norepinephrine infusion, implying endogenous modulation of basal IRI by catecholamines in utero. There was no response in IRG secretion to norepinephrine alone or to phentolamine alone. Although the dose of norepinephrine was modest, it was nevertheless adequate to induce a fall in IRI despite a rise in glucose, and $\alpha$-adrenergic blockade alone induced a rise in IRI. Thus, in the fetal lamb, it appears that insulin secretion is more sensitive to adrenergic modulation by both $\alpha$ and $\beta$-adrenergic receptors, whereas in this study glucagon secretion responded appropriately only to $\beta$-adrenergic modulation. Whether this resistance of IRG secretion to modulation by $\alpha$ adrenergic mechanisms reflects differences in species, in functional maturity, or between intrauterine and extrauterine life cannot be determined from our studies. A similar lack of effect of phentolamine on basal and epinephrine-induced IRG release has been reported (13). However, in those studies reporting positive effects on IRG secretion, the doses of $\alpha$-adrenergic agonists and antagonists used were markedly higher than those in the present study, even after making allowance for differences in size (12).

At the doses used, 2-deoxyglucose failed to elicit significant response in glucose, IRG, or IRI. The intracellular glucopenia induced by 2-deoxyglucose is usually followed by a rebound rise in blood glucose as well as in several hormones including epinephrine and glucagon $(4,5,11,34)$. The adequacy of the counterregulatory response depends on a normally functioning adrenal medulla together with its autonomic innervation because the normal response does not occur in subjects with complete transection of the cervical sympathetic outflow tract (4). Therefore, one possible explanation for our failure to observe responses to 2deoxyglucose in our fetal studies may be functional immaturity of autonomic innervation of the adrenal medulla. Studies in fetal lambs suggest that the catecholamine response to hypoxia consists of 2 components, a direct effect on the adrenal medulla and a component mediated through the splanchnic nerves (7). The latter is only present during the last 15 to 20 days of pregnancy when development of innervation of the sheep fetal adrenal occurs (7). Only two of five animals studied with 2-deoxyglucose were older than 135 days of gestation. Thus, one possible explanation for lack of response to 2-deoxyglucose in the present studies would be functional immaturity of autonomic innervation in the adrenal medulla. It is also possible that the dose of 2-deoxyglucose, although equivalent per unit of body weight to doses used in other studies $(4,5,34)$, was inadequate to produce sufficient intracellular glucopenia in the fetal lamb where plasma glucose is normally only $20 \mathrm{mg} / \mathrm{dl}$. Thus, it has been proposed that glucose is not as important a nutrient for the fetal lamb as for other species, and, therefore, hypoglycemia may not trigger counter regulatory events (14). However, recent studies from our laboratory using glucose 2${ }^{3} \mathrm{H}$ for kinetic analysis demonstrate that per unit of body mass, fetal glucose turnover in the sheep fetus is virtually identical to that of human newborns $(2,3)$. Thus, although inadequacy of dose of 2-deoxyglucose to cause sufficient glucopenia in the sheep fetus remains a possibility, it would seem to be less likely than the inability to respond by increasing catecholamine secretion because of previously demonstrated immaturity of autonomic innervation of the adrenal medulia at the gestational age of our studies (7). Only the measurement of fetal plasma epinephrine concentrations at various gestational ages in response to 2-deoxyglucose can adequately resolve this question.

Overall, the studies indicate that toward the end of the third trimester in fetal sheep, there is appropriate $\alpha$ - and $\beta$-adrenergic modulation of plasma glucose concentration in the presence of elevated glucagon and catecholamine levels, as well as appropriate modulation of insulin and glucagon secretion by the endocrine pancreas. In addition, it is known that the direct response of epinephrine and norepinephrine secretion following a stimulus such as anoxia is established; the indirect response dependent on autonomic innervation of the adrenal medulla becomes established in the final 2 to $3 \mathrm{wk}$ of intrauterine life $(7,8,22)$. Taken in conjunction with the remarkable surge of epinephrine and norepinephrine secretion known to occur at birth $(10,24)$, the demonstration in the present studies that plasma profiles of glucose, IRG, and IRI that normally occur shortly after birth can be simulated by adrenergic agents in utero lends credence to the hypothesis that catecholamines are a major trigger to the metabolic adaptations characteristic of the transition to extrauterine life.

\section{REFERENCES AND NOTES}

1. Anagnostakis, D. E., and Lardinous, R.: Urinary catecholamine excretion and plasma NEFA concentration in small-for-date infants. Pediatrics. 47: 1000 (1971).

2. Anand, R. S.. Sperling. M. A.. Ganguli, S.. and Nathanielsz. P. W.: Bidirectional placental transfer of glucose and its turnover in fetal and maternal sheep. Pediatr. Res., 13: 783 (1979).

3. Bier, D. M. Leake, R. D., Haymond, N. W.. Arnold, K. J., Gruenke, L. D. Sperling. M. A., and Kipnis. D. M.: Measurement of "true" glucose production rates in infancy and childhood with 6.6-diteuteroglucose. Diabetes. 26: 1016 (1977).

4. Brodows, R. G.. Pi-Sunyer, F. X., and Campbell, R. G.: Neural control of counterregulatory events during glucopenia in man. J. Clin. Invest., 52: 184 (1973).

5. Brodows, R. G., Pi-Sunyer, F. X., and Campbell, R. G.: Sympathetic control of hepatic glycogenolysis during glucopenia in man. Metabolism. 24: 617 (1975).

6. Cherrington, A. D., and Exton, J. H.: Studies on the role of cAMP-dependent 
protein kinase in the actions of glucagon and catacholamines on liver glycogen metabolism. Metabolism, 25 (Suppl. 1): 1351 (1976).

7. Comline. R. S.. and Silver, M.: The release of adrenaline and noradrenaline from the adrenal glands of the foetal sheep. J. Physiol.. 156: 424 (1961).

8. Comline. R. S., Silver, I. A.. and Silver. M.: Factors responsible for the stimulation of the adrenal medulla during asphyxia in the foetal lamb. J. Physiol., 178: 211 (1965).

9. Day, J. L.: The metabolic consequences of adrenergic blockade: a review. Metabolism. 24: 987 (1975).

10. Eliot, R. R. Lam, R. Artal, R., Hobel, C., and Fisher. D. A.: Norepinephrine (NE), epinephrine (E), and dopamine (DA) levels at birth in the human in cord and newborn samples. Clin. Res., 26: 198A (1978).

11. Garber, A. H., Cryer. P. E., Santiago. J. V., Haymond. M. W., Pagliara. A. S. and Kipnis. D. M.: The role of adrenergic mechanisms in the substrate and hormonal response to insulin induced hypoglycemia in man. J. Clin. Invest., 58: 7 (1976)

12. Gerich. J. E.. Langlois. M., Noacco, C., Schneider, V., and Forsham, P. H.: Adrenergic modulation of pancreatic glucagon secretion in man. J. Clin. Invest.. 53: 1441 (1974).

13. Gerich, J. E., Lorenzi, M.. Tsalikian. E., and Karam. J. H.: Studies on the mechanism of epinephrine-induced hyperglycemia in man: evidence for participation of pancreatic glucagon secretion. Diabetes, 25: 65 (1976)

14. Girard. J. R.: Metabolic fuels of the fetus. Isr. J. Med. Sci., II: 591 (1975).

15. Girard. J. R., Cuendet, G. S., Marliss. E. B.. Kervran. A.. Rieutort. M.. and Assan. R.: Fuels, hormones and liver metabolism at term. and during the early postnatal period in the rat. J. Clin. Invest., 52: 3190 (1973).

16. Girard. J. R.. Kervran. A.. Soumlet. E., and Assan. R.: Factors affecting the secretion of insulin and glucagon by the rat fetus. Diabetes, 23: 310 (1974)

17. Grajwer. L. A.. Sperling. M. A.. Sack. J., and Fisher. D. A.: Possible mechanisms and significance of the neonatal surge in glucagon secretion: studies in newborn lambs. Pediatr. Res., 11: 833 (1977).

18. Greengard. O.: Enzymatic differentiation of human liver: comparison with the rat model. Pediatr. Res.. 11: 669 (1977).

19. Iversen. J.: Adrenergic receptors and the secretion of glucagon and insulin from the isolated. perfused canine pancreas. J. Clin. Invest., 52: 2102 (1973).

20. Joelsson, I., Barton. M.D. Daniels, S.. James, S., and Adamson K.: The response of the unanesthetised sheep fetus to sympathomimetic amines and adrenergic blocking agents. Am. J. Obstet. Gynecol.. 1/4: 43 (1972).

21. Jones, C. T.: Fetal metabolism and fetal growth. J. Reprod. Fertil., 47: 189 (1976).

22. Jones, C. T., and Robison, R. O.: Plasma catecholamines in foetal and adul sheep. J. Physiol., 248: 15 (1975).

23. Kaneto. A., Kajinuma, H., and Kosaka. K.: Effect of splanchnic nerve stimulation on glucagon and insulin output in the dog. Endocrinology, 96: 143 (1975).

24. Lagercrantz. H., and Bistoletti. P.: Catecholamine release in the newborn infant at birth. Pediatr. Res., 11: 889 (1977).

25. Landsberg, L., and Young. J. B.: Fasting. feeding, and regulation of the sympathetic nervous system. N. Engl. J. Med., 298: 1295 (1978).

26. Lewis, B., Thompson, G. R., and Carlson, L.: Hormones and lipid metabolism. Postgrad. Med. J., 48: 616 (1972).

Copyright @ 1980 International Pediatric Research Foundation, Inc. $0031-3998 / 80 / 1403-0203 \$ 02.00 / 0$
27. Light, I. J., Sutherland. J. M.. Loggie. J. M., and Gaffney, T. E.: Impaired epinephrine release in hypoglycemic infants of diabetic mothers. N. Engl. J. Med.. 277: 394 (1967)

28. Marks. V.: An improved glucose-oxidase method for determining blood, C. S. F., and urine glucose levels. Clin. Chim. Acta. 4: 395 (1959).

29. Marliss, E. B., Girardier, L., Seydoux. J.. Wollheim. C. B., Kanazawa, Y., Orci. L., Renold. A. E.. and Porte, D.. Jr.: Glucagon release induced by pancreatic nerve stimulation in the dog. J. Clin. Invest.. 52: 1246 (1973).

30. Marliss. E. B.. Wollheim. C. B., Blondel. B.. Orci. L.. Lambert. A. E.. Stauffacher. W.. Like. A. A., and Renold. A. E.: Insulin and glucagon release from monolayer cell cultures of pancreas from newborn rats. Eur. J. Clin. Invest., 3: 16 (1973).

31. Nuwayhid. B.. Brinkman, C. R.. Su. C., Bevan. J. A.. and Assali, N. S.: Development of autonomic control of fetal circulation. Am. J. Physiol.. 228: 337 (1975).

32. Porte. D.. Jr., and Robertson. R. P.: Control of insulin secretion by catecholamines, stress, and the sympathetic nervous system. Fed. Proc., 32: 1792 (1973).

33. Robertson. R. P.. and Porte. D.. Jr.: Adrenergic modulation of basal insulin secretion in man. J. Clin. Endocrinol. Metab., 37: 479 (1973).

34. Sizonenko, P. G., Paunier. L.. Valloton. M. B., Cuendet, G. S.. Zahnd. G.. and Marliss. E. B.: Response to 2-deoxy-D-glucose and to glucagon in "ketotic hypoglycemia" of childhood: evidence for epinephrine deficiency and altered alanine availability. Pediatr. Res., 7: 983 (1973).

35. Sperling, M. A., Erenberg, A.. Fiser, R. H., Oh. W.. and Fisher. D. A.: Placental transfer of glucagon in sheep. Endocrinology. 93: 1435 (1973).

36. Sperling. M. A.. DeLamater. P. V.. Fiser. R. H.. Fisher, D. A.. and Kazenelson. $M$.: Development and application of radioimmunoassay for glucagon. Clin. Chem.. 20: 566 (1974).

37. Sperling. M. A., DeLamater, P. V., Phelps. D., Fiser, R. H.. Oh. W., and Fisher, D. A.: Spontaneous and amino acid-stimulated glucagon secretion in the immediate post-natal period. Relation to glucose and insulin. J. Clin. Invest.. 53: 1159 (1974)

38. Woods. S. C., and Porte. D.. Jr.: Neural control of the endocrine pancreas. Physiol. Rev. 54: 593 (1974).

39. A portion of this work was presented at the Western Society for Pediatric Research. Carmel, California. February 1978. [Clin. Res., 26: 197A (abstract)].

40. Requests for reprints should be addressed to: Dr. Mark Sperling, Children's Hospital Medical Center, Cincinnati, Ohio 45229 (USA).

41. This research was supported by grants from The National Institute of Child Health and Human Development. National Institute of Health (HD 07087 and HD 04270), Juvenile Diabetes Foundation, and American Diabetes Association, Southern California.

42. Doctor Sperling is a recipient of a Research Career Development Award from the United States Public Health Service (IK04 HD 00029).

43. Received for publication October 31. 1978.

44. Accepted for publication April 24. 1979 